EPJ Web of Conferences 44, 03006 (2013)

DOI: $10.1051 /$ epjconf/20134403006

(C) Owned by the authors, published by EDP Sciences, 2013

\title{
Spectroscopic ellipsometry, optical, structural and electrical investigation of sprayed pure and Sn-doped $\mathrm{ZnO}$ thin films
}

\author{
Mokhtari H. ${ }^{(1, *)}$, Benhaliliba M. ${ }^{(1)}$, Aida M.S. ${ }^{(2)}$, AttafN. ${ }^{(2)}$ and Y. Ocak ${ }^{(3)}$ \\ (1) Physics Department, Sciences Faculty, USTO-MB University, BP1505 Oran, Algeria. \\ (2) Laboratory of thin films and plasma Mentouri University, 25000 Constantine, Algeria. \\ (3) Department of Science, Faculty of Education, Dicle University, Diyarbakır, Turkey.
}

\section{Keywords:}

\begin{abstract}
Sn-doped zinc oxide $(\mathrm{ZnO})$. The films were deposited onto microscope glass substrate which was heated at $350 \pm 5 \mathrm{C}^{\circ}$ by ultrasonic spray pyrolysis (U S P) deposition technique. The concentrations of $\mathrm{Sn}$ were selected within the range of $0-3 \%$ by step of $0.5 \%$ and the time deposition is kept at $5 \mathrm{~min}$. A (002)-oriented wurtzite crystal structure was confirmed by X-rays patterns; and grain size varied within the range $7.37-14.84 \mathrm{~nm}$, and cristanillity is calculated goes from 14.4 to $45.9 \%$. Based on UV-VIS-IR analysis, the results revealed the high transparency of the sprayed films which exceeds $90 \%$. The band gap energy was of $3.26-3.30 \mathrm{eV}$. The film thickness was estimated by spectroscopy ellipsometry and the found values were of $165-270 \mathrm{~nm}$. The refractive index is in the range of 2.75 . The obtained electrical parameters were around $10^{18} \mathrm{~cm}^{-3}, 3.6 \mathrm{~cm}^{2} / \mathrm{Vs}, 1.6 \Omega . \mathrm{cm}$;

$5.8 \mathrm{~cm}^{3} / \mathrm{C}$. finally the $\mathrm{Sn}$-doping has influenced the physical parameters of asground $\mathrm{ZnO}$ films
\end{abstract}

$\mathrm{ZnO}$; ultrasonic spray pyrolysis; Sn-doping; X-rays patterns; optical properties; electrical properties; spectroscopy ellipsometry; refractive index.

\section{Introduction}

Zinc oxide $(\mathrm{ZnO})$ is an n-type semiconductor which it's recently gained much attention due to many advantages over other oxide thin films with its direct wide band gap of 3.30-3.39 eV [1]; and the large exciton binding of $60 \mathrm{meV}$ [2]. $\mathrm{ZnO}$ is mechanically and chemically stable with wurtzite structure and the lattice parameters are $\mathrm{a}=3.25 \mathrm{~A}^{\circ}$ and $\mathrm{c}=5.19 \mathrm{~A}^{\circ}[3]$

The resistivity value of $\mathrm{ZnO}$ can be tuned between $10^{-4}$ and $10^{12} \Omega \mathrm{cm}$ which it can be controlled by adjusting doping and preparation parameters [1].

Pure and Sn-doped $\mathrm{ZnO}$ has been used in many applications as gas sensors, solar cells windows, transparent electrode [1], [2], [3].

$\mathrm{ZnO}$ films can be produced by several techniques such as sol-gel process [4].chemical vapor deposition [5], sputtering [6], pulsed laser ablation [7] and ultrasonic spray pyrolysis (USPD)

[8].

USPD is a facile, unobstructive, low cost and non-toxic deposition technique.

Up to our knowledge, few works on Sn-doped $\mathrm{ZnO}$ films fabricated by USPD have been achieved. In this work, structural, optical, spectroscopic ellipsometry and electrical properties of as-deposited $\mathrm{ZnO}$ films produced by USPD were investigated and the role of Sn-doping on physical properties of $\mathrm{ZnO}$ films was emphasized. 


\section{Experimental procedure}

\subsection{Preparation of sprayed $\mathrm{ZnO}$ films}

$\mathrm{ZnO}$ films were deposited by USPD route from zinc acetate $\left(\mathrm{Zn}\left(\mathrm{CH}_{3} \mathrm{COO}\right)_{2}, 2 \mathrm{H}_{2} \mathrm{O}\right)$ used as precursor. $0.1 \mathrm{~mol}$ of zinc acetate was dissolved in $100 \mathrm{ml}$ of methanol. Tin doping was added from the tin chloride $\left(\mathrm{SnCl}_{2}\right)$ to the precursor with different concentrations from 0 to $3 \%$ by step of $0.5 \%$.

The used substrates were the microscope glass which they were chemically successively cleaned by methanol for $15 \mathrm{~min}$ and distilled water for $20 \mathrm{~min}$. We deposit our films at fixed substrate temperature of $350{ }^{\circ} \mathrm{C}$ and the time deposition was $5 \mathrm{~min}$ and the distance nozzlesubstrate was around $5 \mathrm{~cm}$. The substrate must be placed under nozzle before the temperature reaches $50 \mathrm{C}^{\circ}$ to avoiding the thermal chock as shown in figure 1.

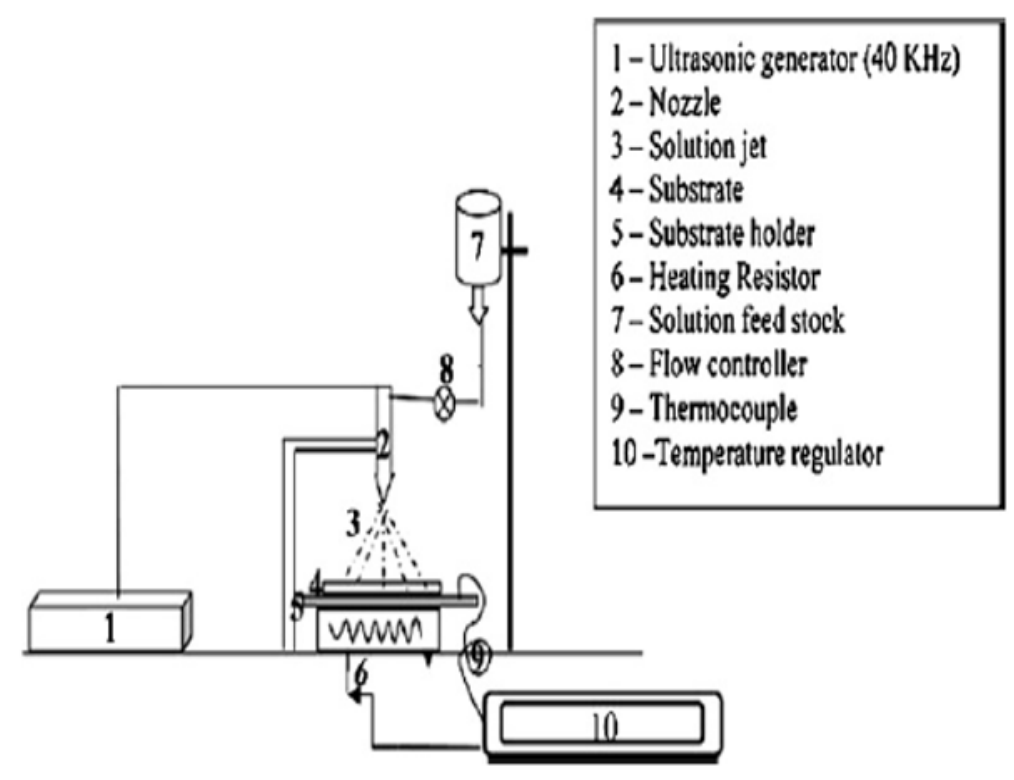

Fig.1: Schematic diagram of USP system set-up

\subsection{Characterizations of as-grown films}

Room temperature X-rays diffraction pattern of pure and $\mathrm{Sn}$-doped $\mathrm{ZnO}$ films were carried out by Bruker (D8 ADVANCE with DAVINCI design) diffractometer in $2 \theta$ range of $20-80^{\circ}$. The transmittance and absorbance were calculated by two beams Shimadzu spectrophotometer (UV-VIS-IR spectrophotometer Shimadzu UV-3600).

The thickness of films were taken by spectroscopic ellipsometry (we use Ellipsometer PHE102) which is an optical technique used for analysis and metrology. The light beam is reflected by the sample which will be detected by a sensor and then analyzed to see what the sample did to the light beam and finally we draw conclusion about the simple (as thickness show in table 1).

\begin{tabular}{ccc}
\hline $\begin{array}{c}\mathrm{Sn} / \mathrm{Zn} \\
(\%)\end{array}$ & $\begin{array}{c}\text { Thickness } \\
(\mathrm{nm})\end{array}$ & $\begin{array}{c}\mathrm{Eg} \\
(\mathrm{eV})\end{array}$ \\
\hline 0 & 262 & 3.26 \\
1.5 & 221 & 3.28 \\
2 & 165 & 3.29 \\
2.5 & 236 & 3.28 \\
3 & 270 & 3.28 \\
\hline
\end{tabular}

Table1: Thickness and optical band gap of pure and Sn-doped $\mathrm{ZnO}$ films 
The electrical parameters such as bulk density, resistivity and mobility were measured by Hall measurement system (HMS)

\section{Results and discussion}

In this work, the films selected were those grown from $0.1 \mathrm{M}$ at $350^{\circ} \mathrm{C}$ during a deposition time of $5 \mathrm{~min}$.

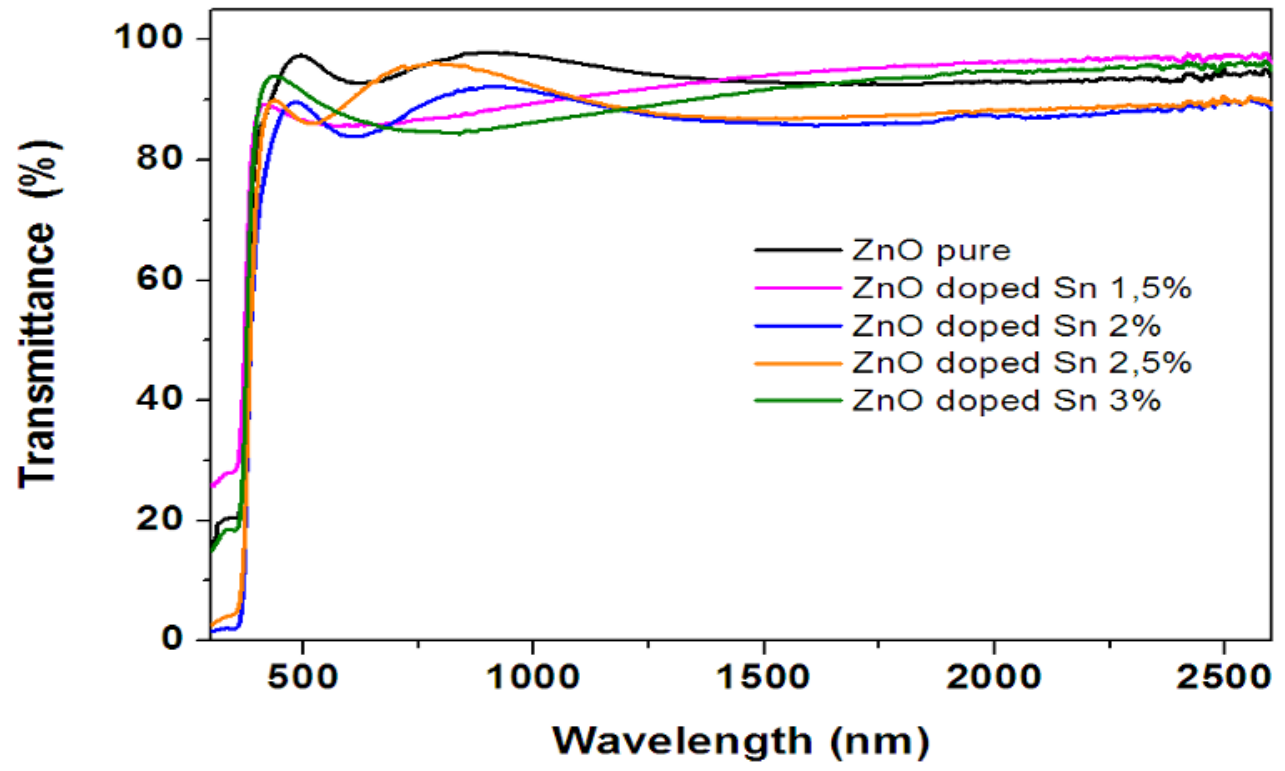

Fig. 2: transmittance spectra of $\mathrm{Sn}-\mathrm{ZnO}$ thin films

We note that the films are highly transparent in the visible region and low in ultraviolet region. The transmittance is higher than $90 \%$ with an absorption edge between $380 \mathrm{~nm}$ and $420 \mathrm{~nm}$ depending on the deposition parameters.

The interference fringes of the transmittance curves revealed that the films surface is smooth and highly reflecting, there is no match scattering or absorption loss in the films.

It has observed that the absorption edges of doped $\mathrm{ZnO}$ are slightly shifted to the shorter wavelength (blue shift); this is mainly attributed to the Burstein-Moss effect [9].

The variation of $(\alpha h v)^{2}$ as a function of the photon energy hv of the pure and $\mathrm{Sn}$ doped $\mathrm{ZnO}$ are sketched in Fig.3 the optical band gap for as-grown films is obtained by the intercept of the straight line on the horizontal axis.

\section{1 optical properties}

The transmittances of prepared thin films were collected by using UV-VIS-IR spectrophotometer. The value of transmittances spectra were measured by taking a similar glass as a reference to compare it with our films, hence the spectra were from the film only. The thicknesses of as-deposited films were calculated by using spectroscopy ellipsometry. The obtained results range within 160 and $270 \mathrm{~nm}$ depend strongly on doping level. The results are plotted in Fig. 2 as a function of wavelength $\lambda$ from $300 \mathrm{~nm}$ to $2500 \mathrm{~nm}$. 


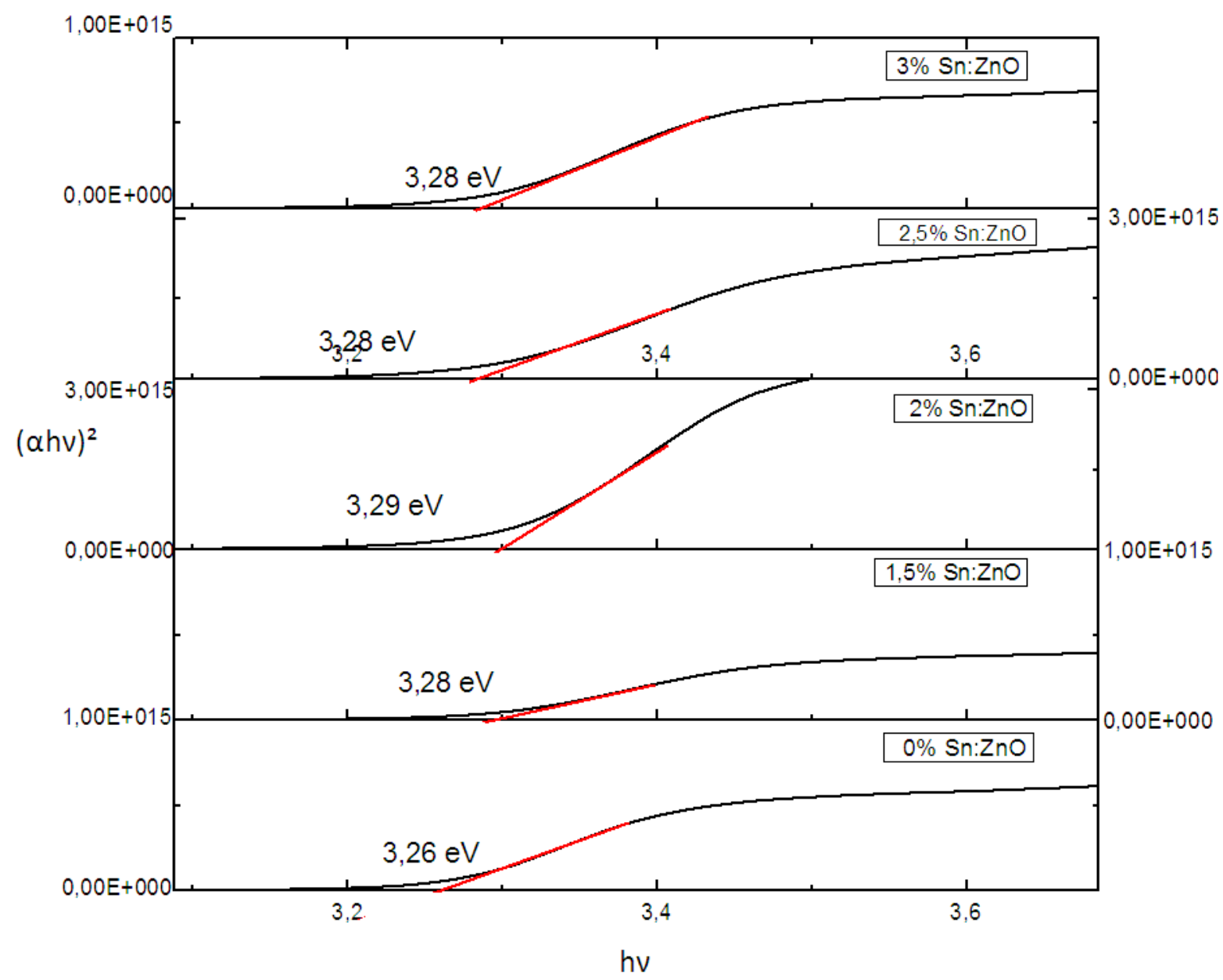

Fig 3: plot of $(\alpha h v)^{2}$ vs hv of pure $\mathrm{ZnO}$ and doped $\mathrm{Sn}$

\section{2 structural properties}

The cristallinity and the preferred crystal orientation of the undoped and Sn doped $\mathrm{ZnO}$ films were analyzed by XRD method by Bruker D8 ADVANCE with DAVINCI design diffractometer as shown in Fig.4

\begin{tabular}{|c|c|c|c|c|c|}
\hline $\begin{array}{c}\text { Films } \\
\mathrm{Sn} / \mathrm{Z} \\
\mathrm{n} \\
(\%)\end{array}$ & $\begin{array}{c}2 \theta \\
\left({ }^{\circ}\right)\end{array}$ & $\begin{array}{c}\Delta \theta \\
\left({ }^{\circ}\right)\end{array}$ & $\begin{array}{c}\mathrm{d} \\
\left(\mathrm{A}^{\circ}\right)\end{array}$ & $\begin{array}{c}\text { Cristani } \\
\text { llity } \\
(\%)\end{array}$ & $\begin{array}{c}\text { Grain } \\
\text { Size } \\
(\mathrm{nm})\end{array}$ \\
\hline 0 & 33.48 & 0 & 2.65 & $31.1 \%$ & 14.84 \\
\hline 1.5 & 34.00 & -0.52 & 2.60 & $45.9 \%$ & 7.37 \\
\hline 2 & 33.27 & 0.21 & 2.70 & $28.3 \%$ & 9.19 \\
\hline 2.5 & 33.36 & 0.12 & 2.68 & $42.3 \%$ & 11.33 \\
\hline 3 & 33.01 & 0.47 & 2.71 & $14.4 \%$ & 9.81 \\
\hline
\end{tabular}

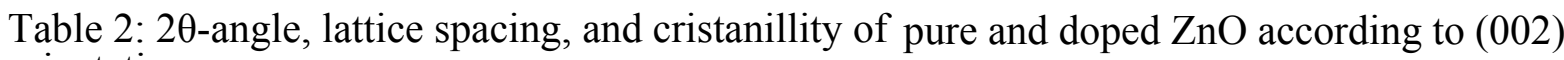
orientation 


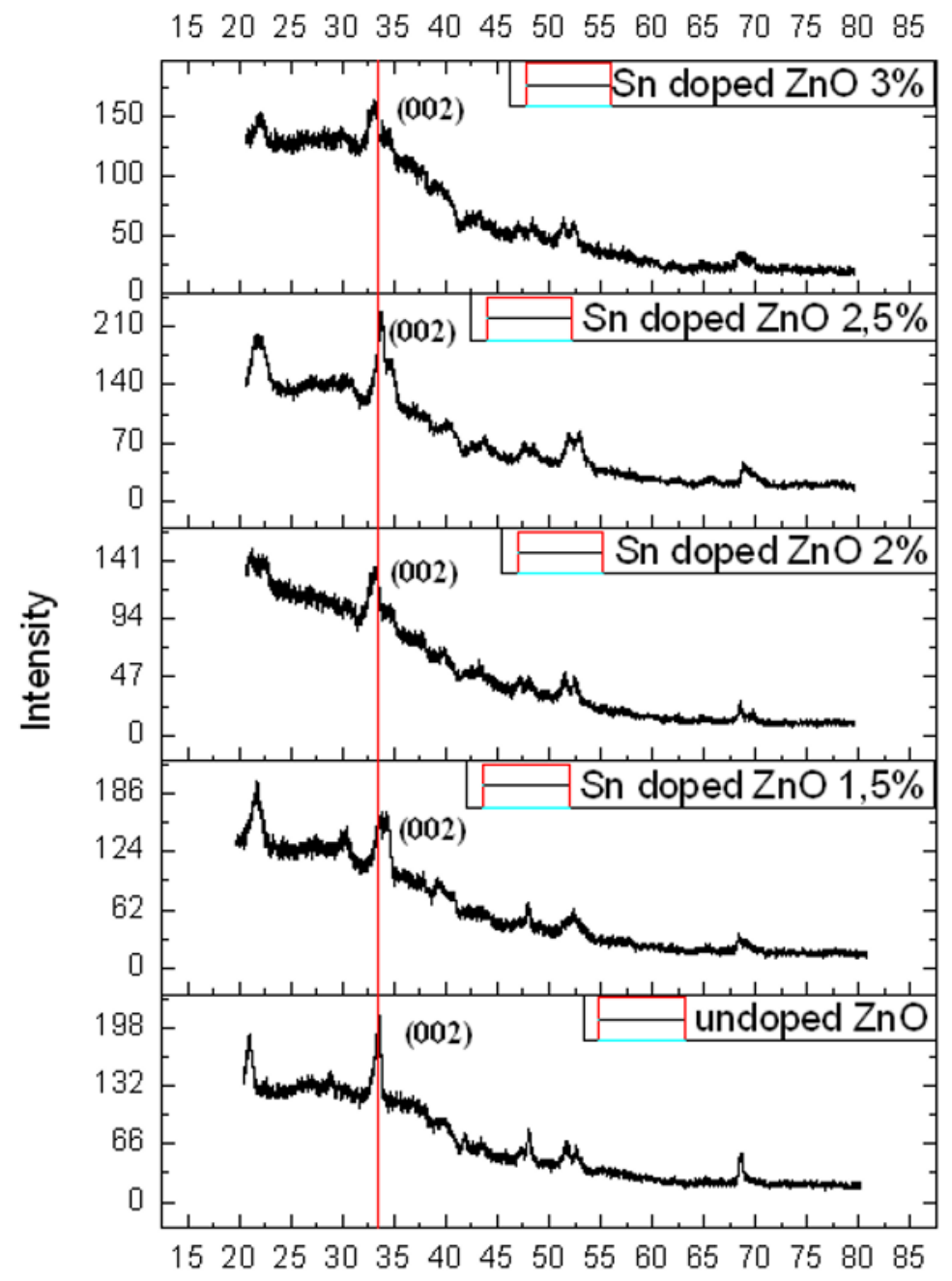

Fig.4: XRD spectra of undoped and $\mathrm{Sn}$ doped $\mathrm{ZnO}$

Fig. 4 shows that the films are polycrystalline with a hexagonal wurtzite type structure (ASTM 89-1357). And shows a high diffraction intensity for (002) peak hence the films exhibit preferential orientation along the (002) plane.

The lattice spacing, Bragg angle and percentage of cristallinity and the angle shift $\Delta \theta$ is determined as $2 \theta$ (pure $\mathrm{ZnO}$ )-2 $\theta$ (doped $\mathrm{ZnO}$ ) are listed in table 2.

The first peak located at $\sim 22^{\circ}$ corresponds to amorphous carbon comes from zinc acetate ( $\mathrm{Zn}$ $\left.\left(\mathrm{CH}_{3} \mathrm{COO}\right)_{2}, 2 \mathrm{H}_{2} \mathrm{O}\right)$, amorphous carbon's peak is sited in Zhou Kong's work [25]

The lattice spacing was calculated by the Bragg law [3]:

$$
\mathrm{n} \lambda=2 \mathrm{~d} \sin \theta
$$

Where $\theta$ is half of Bragg angle, $\mathrm{d}$ is the lattice spacing, $\mathrm{n}$ is diffraction order and $\lambda$ is the $\mathrm{X}$ ray wavelength.

The grain sizes were calculated by Scherer's formula:

$$
\mathrm{G}=(0.94 \lambda) / \beta \operatorname{Cos} \theta
$$

Where $\beta$ is the full width at half maximum.

It is observed that doping include a shift angle for the main orientation of the $\mathrm{ZnO}$ films. JCPDS card of $\mathrm{ZnO}$ shows that (002) is peaked at $34.46^{\circ}$. 


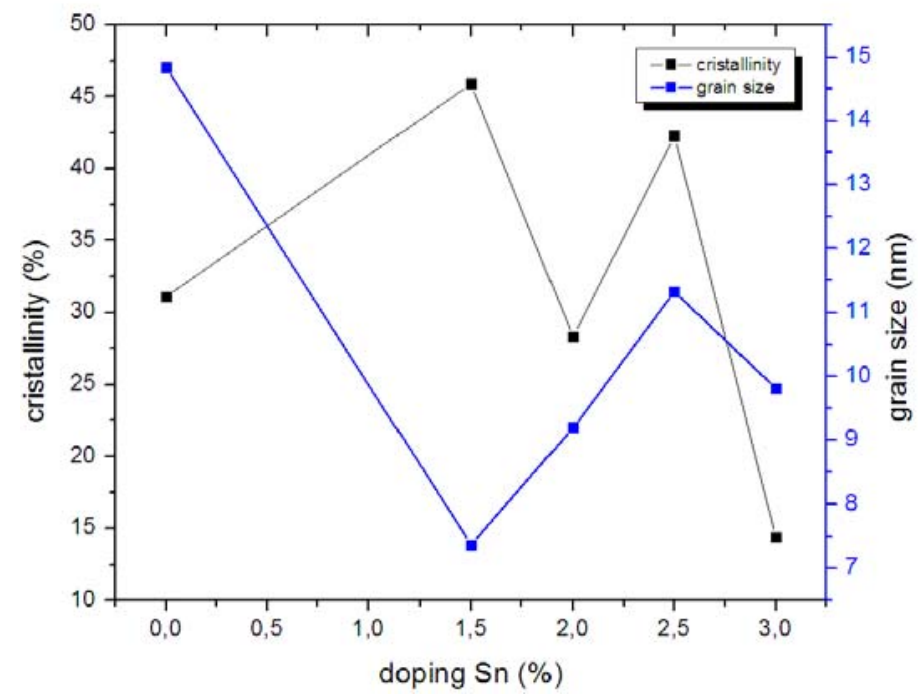

Fig.5: show the grain size versus doping Sn

Fig. 5 show the graphs of cristallinity and grain size versus percentage of $\mathrm{Sn}$ as dopant If we take undoped $\mathrm{ZnO}$ film as an example we can say that the film is $31.1 \%$ crystallized in groups of grain size $\pm 14.84 \mathrm{~nm}$.

We observe that the grain size of doped $\mathrm{ZnO} 2 \%$ and $3 \%$ films is bigger than $1.5 \% 2.5 \%$ films with lower cristallinity as table 2 shown, its maybe due to the influence of thickness of films and/or the influence of the lattice spacing $\mathrm{d}\left(\mathrm{A}^{\circ}\right)$. The cristallinity increase with decreasing of lattice spacing as it's shown in Fig.6.

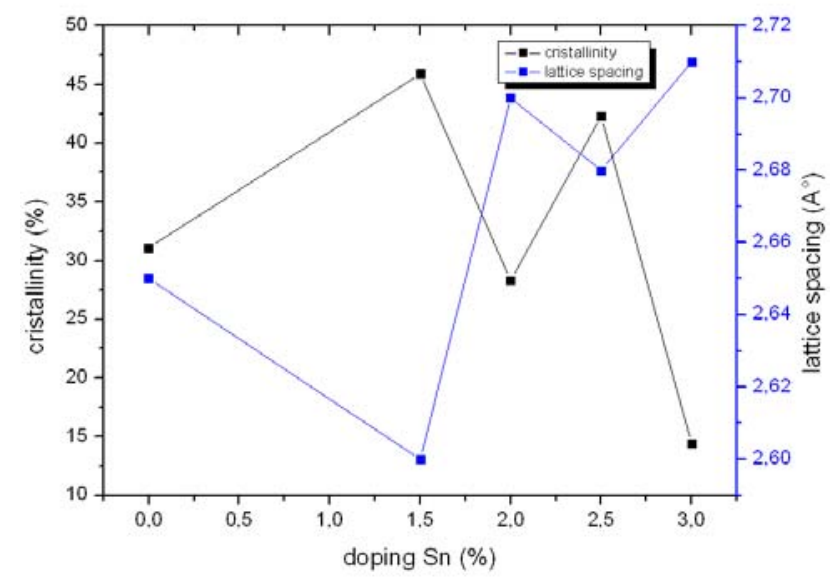

Fig.6: plot of cristallinity, lattice spacing versus doping Sn

\subsection{Electrical properties}

The current-voltage (I-V) measurements of all films have been carried out by using fourprobe method at room temperature $(300 \mathrm{~K})$, which the sample was held between four gold contacts as sketched in Fig.7.

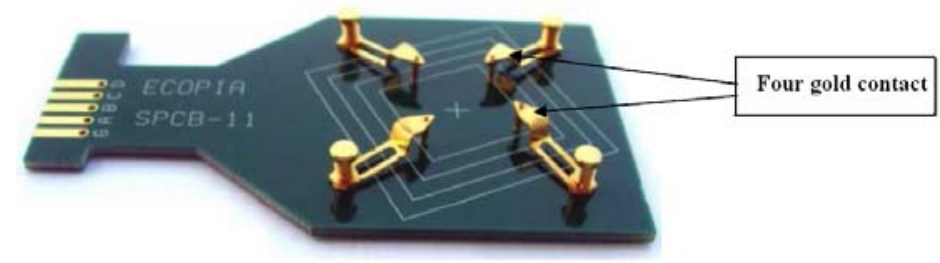

Fig.7: gold contact used in the measurement of electrical properties 
$\mathrm{ZnO}$ has a wide range of electrical conductivity which it can be controlled by doping. The variation of electrical conductivity with doping Sn is shown in Fig.8.

It is shown that the conductivity increase with increasing of doping $\mathrm{Sn}$, it can be explained by the substation of $\mathrm{Zn}^{+2}$ by $\mathrm{Sn}^{+4}$ in $\mathrm{ZnO}$ crystal structure which resulting in two more free electron to contribute to the electrical conduction.

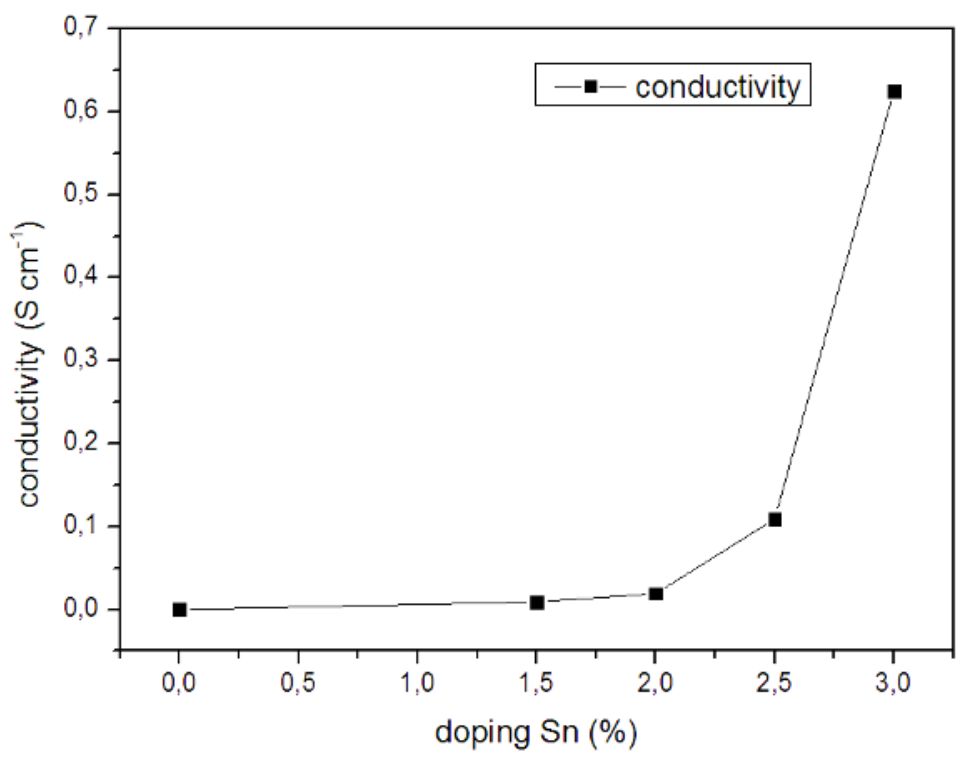

Fig.8: plot of electrical conductivity versus doping Sn

Table3 show the electrical parameters as bulk density, mobility, resistivity, hall coefficient.

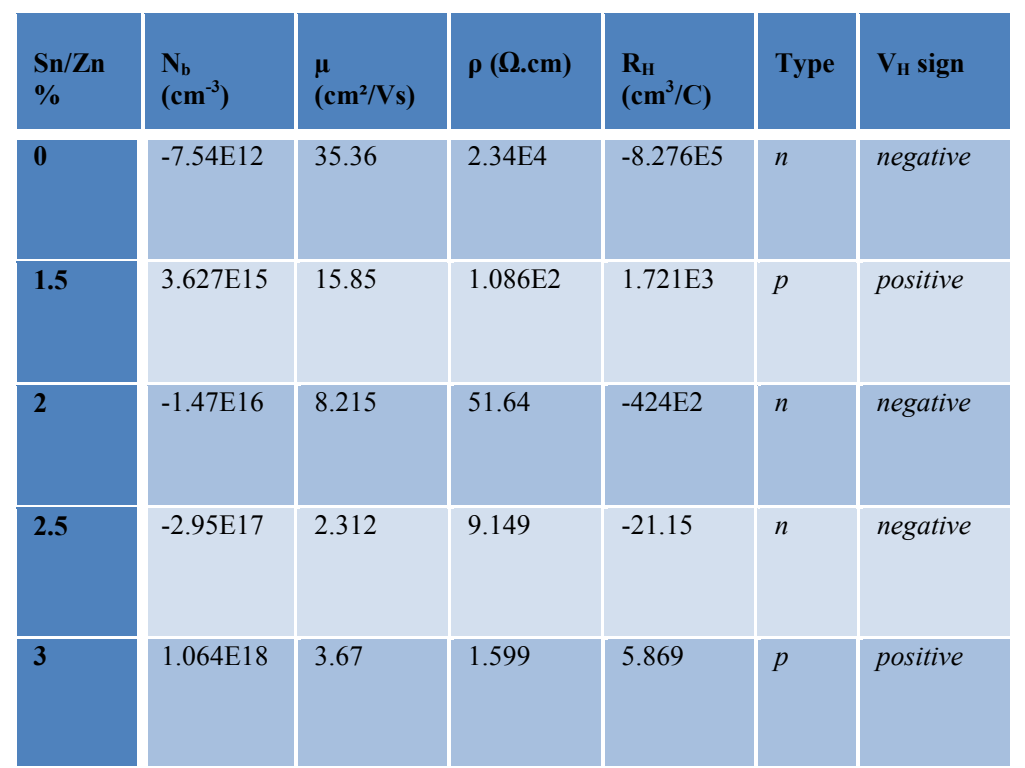

Table3: bulk density, mobility, resistivity, hall coefficient. 


\subsection{Spectroscopy ellipsometry}

Spectroscopy ellipsometry (SE) known for its precision and non-destructive, by measuring the change in the light polarization stat as psi $(\psi)$ and delta $(\Delta)$ which represent the amplitude ratio and phase difference between $p$ - and s-polarization respectively of the reflected light off the surface of the film. [10.11.12]

SE was use to measure the optical constant at an incidence angle of $70^{\circ}$ as it's shown at Fig.9 and It's found that the calculated $\psi$ and $\Delta$ are consistent with the experimental data for all films.

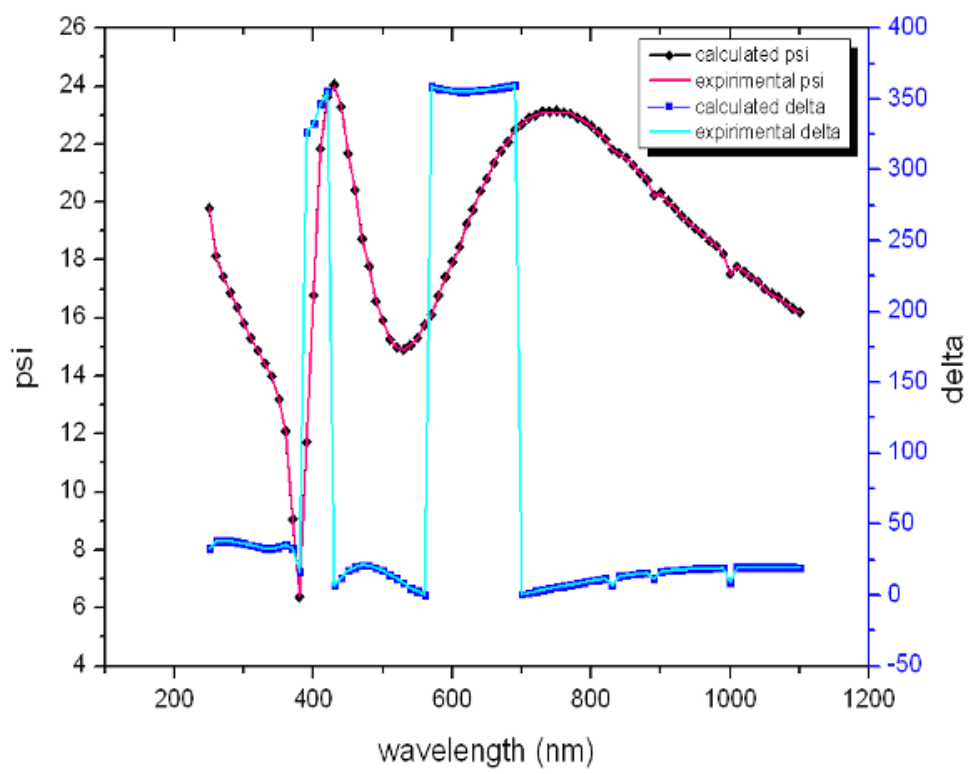

Fig.9: ellipsometry spectra of undoped $\mathrm{ZnO}$

The optical constants are very important to designing the optical devises, because of their relation to the electronic polarize-ability of ions and the local field inside materials [12]. Thus it's important to determine the refractive index (n) and extinction coefficient $(\mathrm{k})$ of the films. The dielectric function can be determinate from the optical parameters $(\mathrm{n})$ and $(\mathrm{k})$ by:

$\varepsilon_{1}=\mathrm{n}^{2}-\mathrm{k}^{2}$

$\varepsilon_{2}=2 \mathrm{nk}$

Fig.11 show (n) and (k) of the rest of films which has same reaction with doping Sn. 


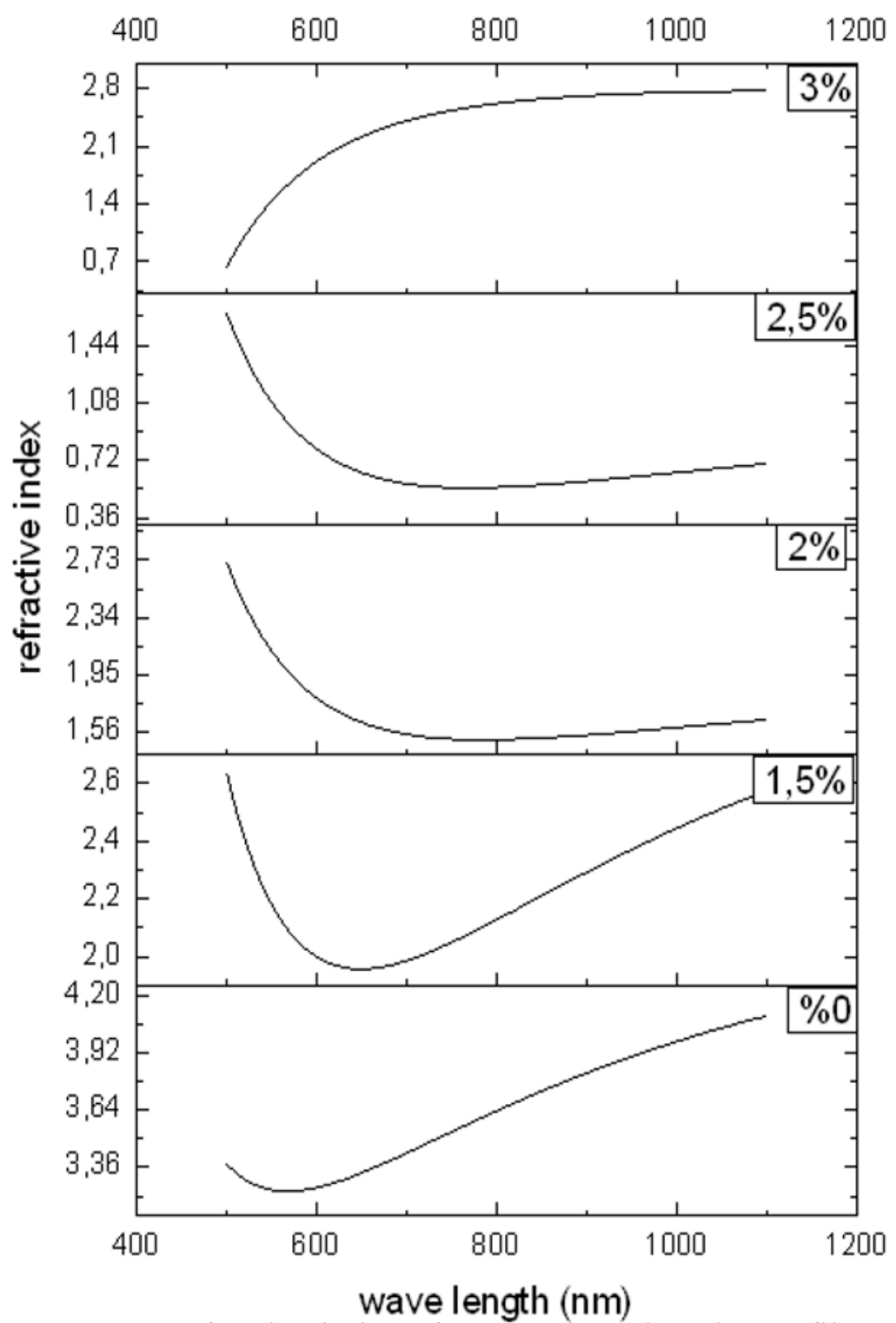

Fig.11: refractive index of pure and $\mathrm{Sn}$-doped $\mathrm{ZnO}$ films 
Fig. 12 and Fig.13 show the variation of the real and imaginary values of dielectric function.
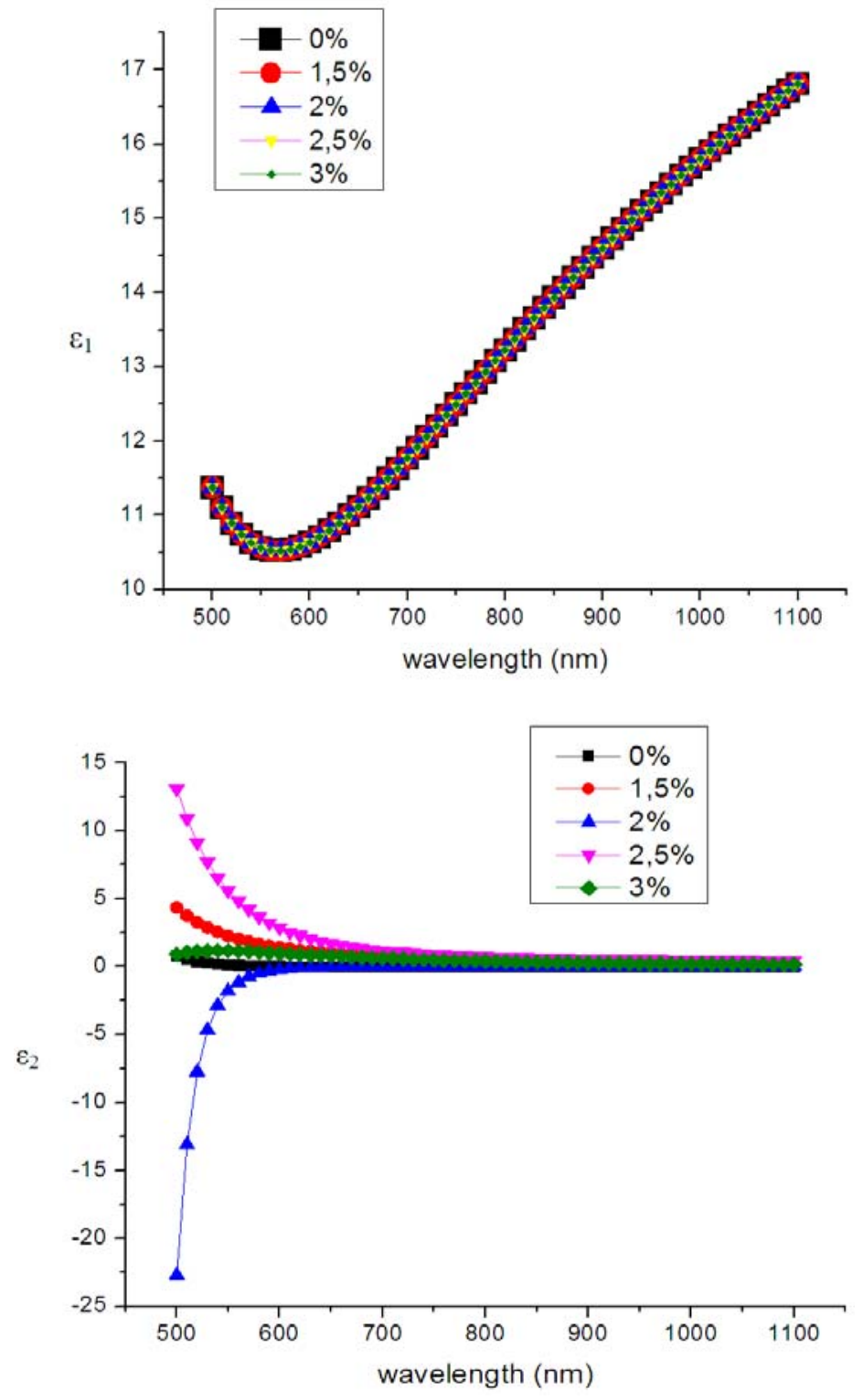

Fig.12: real part of dielectric function of undoped and doped $\mathrm{ZnO}$
Fig.13: imaginary part of dielectric function of undoped and doped $\mathrm{ZnO}$

We observe that we have the same values of $\varepsilon_{1}$ for all films, it means that the films of pure and $\mathrm{Sn}$-doped $\mathrm{ZnO}$ films have the same real part of the dielectric function.

The imaginary part of the dielectric function are shown in Fig.13 which we can observe the reaction of dielectric function with Sn-doping. 


\section{Conclusion}

The impact of tin doping on optical, structural, electrical and spectroscopy ellipsometry of Zinc oxide by ultrasonic spray pyrolisys deposition are investigated.

The optical parametre shows that the films of undoped and doped $\mathrm{ZnO}$ are highly transparent and the band gap energy was shifted from $3.26 \mathrm{eV}$ to $3.28 \mathrm{eV}$ by Burstein-Moss effect due to the introduction of Sn impurty which leads to.

The structural caracterization reveald that the films prefer plan (002) as a preferentiel orientation with best cristanillity is for $\mathrm{ZnO}$ doped $\mathrm{Sn}$ a $1.5 \%$. which is due to the lowest value of spacing lattice.

The electrical studies show the possibility to get p-type zinc oxide and reveals that the decrease of resistivity due to the increase of the bulk density.

Spectroscopy ellipsometry reveal the optical parameter of $\mathrm{ZnO}$ and show that the refractive index decrease with doping increase and that's due to the change of structure of $\mathrm{ZnO}$ by introduction of Sn as impurty. The data of SE reveal that the doping doesn't affect the real part of dielectric function but the imaginary.

\section{Acknowledgements}

The work is included in the PNR project under contract number 8/U311/R77, supported by "agence thématique pour la recherche scientifique et technologique" (ATRST) http://www.atrst.dz, and national administration of scientific research (NASR) www.nasr.dz. This work is a part of CNEPRU project $n^{\circ}$ D01920120039 supported by Oran university of sciences and technology USTO-MB. The first and second authors are grateful for the assistance of Dicle University-Diyarbakir-Turkey, Mentouri University of Constantine and the virtual library of SNDL https://www.sndl.cerist.dz

\section{References}

[1]Shalaka C. Navale, I.S. Mulla, Materials Science and Engineering C 29 (2009) 1317-1320.

[2]M.M.Islama, S. Ishizuka, A. Yamada, K. Matsubara, S. Niki, T. Sakurai, K. Akimoto, Applied Surface Science 257 (2011) 4026-4030.

[3]Jun-ichi Nomoto, Tomoyasu Hirano, Toshihiro Miyata, Tadatsugu Minami, Thin Solid Films 520 (2011) 1400-1406.

[4]M. Benhaliliba - C. E. Benouis, A. Tiburcio Silver, Journal of Technology and Materials JNTM vol.01, $\mathrm{N}^{\circ} 00(2011)$ 24-28.

[5]Peng Hu, Ning Han, Dangwen Zhang, Johnny C. Ho, Yunfa Chen, Sensors and Actuators B 169 (2012) 74-80.

[6]V. Ghafouri, M. Shariati, A. Ebrahimzad, Scientia Iranica F (2012) 19 (3), 934-942.

[7]S.J. Henley, M.N.R. Ashfold, D. Cherns, Surface and Coatings Technology $177-178$ (2004) 271276.

[8]M. Benhaliliba • C. E. Benouis • M. S. Aida • F. Yakuphanoglu • A. Sanchez Juarez, J Sol-Gel Sci Technol (2010) 55:335-342.

[9]Y.H. Hwang, H.M. Kim, Y.H. Um, H.Y. Park, Materials Research Bulletin 47 (2012) 2898-2901.

[10]T.W.H. Oates, H. Wormeester, H. Arwin, Progress in Surface Science 86 (2011) 328-376.

[11]Gregory J. Exarhos, Aimee Rose, Charles F. Windisch Jr, Thin Solid Films 308-309 (1997) 5662.

[12]Á. Németh, Cs. Major, M. Fried, Z. Lábadi, I. Bársony, Thin Solid Films 516 (2008) 7016-7020.

[13]M. Benhalilba, C.E. Benouis, M.S Aida , A.Sanchez Juarez, F. Yakuphanoglu, A. Tiburcio-Silver, J. Alloys Compds, 506(2010)548-553.

[14]C.E. Benouis, M. Benhalilba, J.Sanchez, M.S Aida, F. Chami,f. Yakuphangulo, J.Alloys and Compds, 490(2010)62-67.

[15]A.D. Acharya, Shweta Moghe, Richa Panda, S.B. Shrivastava, Mohan Gangrade, T. Shripathi, D.M. Phase, V. Ganesan, Journal of molecular structure 1022 (2012) 8-15. 
[16]Paul. GK, Sen. GK, optical properties of some sol gel-derived gallium doped $\mathrm{ZnO}$, materials letters 2002; 57:959-63.

[17]Bengisu Ergin, Elif Ketenci, Ferhunde Atay, international journal of hydrogen energy 34 (2009)5249-5254.

[18]Qing Hua Li, Deliang Zhu, Wenjun Liu, Yi Liu, Xiao Cui Ma, Applied Surface Science 254 (2008) 2922-2926.

[19]R. Schmidt-Grund, Thin Solid Films 519 (2011) 2777-2781.

[20]H. Neumann, W. Horing, E. Reccius, Thin Solid Films 61 (1979) 13

[21]A. El Hichou, Thin Solid Films 518 (2010) 4150-4155

[22]Lila Raj Dahal, Thin Solid Films 519 (2011) 2682-2687

[23]E. Zaleta-Alejandre, Thin Solid Films 524 (2012) 44-49

[24]Hiroyuki Fujiwara, Spectroscopic Ellipsometry Principles and Applications, ISBN-13: 978-0-47001608-4 (cloth: alk. paper)

[25] Ji-Zhou Kong $\bullet$ Fei Zhou $\bullet$ Zheng Wang $\bullet$ Chuan-Bao Wang $\bullet$ Mei-Ling Wang $\bullet$ Kang-Min Chen

-Xue-Mei Wu・Kong-Jun Zhu•Jin-Hao Qiu, J Sol-Gel Sci Technol (2012) 63:95-102 